\section{(A) Check for updates}

Cite this: Nanoscale, 2020, 12, 13540

\title{
Silicon oxycarbide-antimony nanocomposites for high-performance Li-ion battery anodes $\uparrow$
}

\author{
Romain J.-C. Dubey, (D) a,b Pradeep Vallachira Warriam Sasikumar, (D) \\ Noemi Cerboni, ${ }^{a}$ b Marcel Aebli, ${ }^{a, b}$ Frank Krumeich, (D) a Gurdial Blugan, (D) ${ }^{c}$ \\ Kostiantyn V. Kravchyk, (D) a,b Thomas Graule*c and Maksym V. Kovalenko (D)*a,b
}

Silicon oxycarbide $(\mathrm{SiOC}$ ) has recently regained attention in the field of $\mathrm{Li}$-ion batteries, owing to its effectiveness as a host matrix for nanoscale anode materials alloying with Li. The SiOC matrix, itself providing a high Li-ion storage capacity of $600 \mathrm{~mA} \mathrm{~h} \mathrm{~g}^{-1}$, assists in buffering volumetric changes upon lithiation and largely suppresses the formation of an unstable solid-electrolyte interface. Herein, we present the synthesis of homogeneously embedded Sb nanoparticles in a SiOC matrix with the size of 5-40 nm via the pyrolysis of a preceramic polymer. The latter is obtained through the Pt-catalyzed gelation reaction of $\mathrm{Sb}$ 2-ethylhexanoate and a poly(methylhydrosiloxane)/divinylbenzene mixture. The complete miscibility of these precursors was achieved by the functionalization of poly(methylhydrosiloxane) with apolar divinyl benzene side-chains. We show that anodes composed of $\mathrm{SiOC/Sb}$ exhibit a high rate capability, delivering charge storage capacity in the range of 703-549 mA h g ${ }^{-1}$ at a current density of 74.4-2232 $\mathrm{mA} \mathrm{g}^{-1}$. The impact of $\mathrm{Sb}$ on the $\mathrm{Si}-\mathrm{O}-\mathrm{C}$ bonding and on free carbon content of $\mathrm{SiOC}$ matrix, along with its concomitant influence on Li-ion storage capacity of SiOC was assessed by Raman and ${ }^{29} \mathrm{Si}$ and ${ }^{7} \mathrm{Li}$ solid-state NMR spectroscopies.

Received 13th April 2020

Accepted 10th June 2020

DOI: $10.1039 / \mathrm{dOnr02930k}$

rsc.li/nanoscale alloying-type NPs, the utilization of a suitable embedding matrix was determined to be the most effective strategy. ${ }^{10}$ The matrix should spatially disentangle the alloying reaction and the contact of the NPs with the liquid electrolyte, while efficiently buffering their volume changes upon lithiation. The design of a suitable matrix is highly challenging since it must meet stringent requirements in terms of mechanical stability, Li-ion and electrical conductivity, volumetric, and gravimetric charge storage capacity. The majority of the proposed syntheses of a suitable matrix meet these requirements; however, at the cost of utmost pricey and lengthy synthesis procedures. $^{11,17}$

Silicon oxycarbide (SiOC) is a highly appealing candidate matrix material for stabilization of alloying-type inclusions. ${ }^{18}$ SiOC is an amorphous ceramic material with a complex tetrahedrally bonded network comprising $\mathrm{Si}, \mathrm{O}$, and $\mathrm{C}$, and commonly containing also free carbon $\left(\mathrm{C}_{\text {free}}\right)$ nanodomains. ${ }^{19,20}$ This material is attractive for its ability to serve as an active matrix owing to its highly reversible intrinsic Li-ion storage properties $\left(\sim 600 \mathrm{~mA} \mathrm{~h} \mathrm{\textrm {g } ^ { - 1 }}\right)^{21}$ originating mainly from the quality of its $\mathrm{C}_{\text {free }}$ domains. ${ }^{22,23}$ The level of disorder in the $\mathrm{C}_{\text {free }}$ phase is decisive for high Li-ion storage capacity and kinetics. ${ }^{24-26}$ Furthermore, SiOC is a low-cost material and it undergoes low volumetric expansion upon lithiation $(7 \%){ }^{21}$ Some recent examples of the effectiveness of SiOC matrix for 
improving the cycling stability of alloying-type anodes include the stabilization of $\mathrm{Sn} \mathrm{NPs}{ }^{18,27,28}$ and diverse kinds of $\mathrm{Si}$ NPs. ${ }^{29-31}$

In this work, we were motivated to test SiOC as a matrix for the impregnation of alloying-type $\mathrm{Sb}$ nanoinclusions. We note that the synthesis of SiOC/Sb was already demonstrated by Lee et al. $^{32}$ that involves mixing of silicone oil and $\mathrm{Sb}$ acetate ( $\mathrm{Sb}$ $(\mathrm{Ac})_{3}$ ) at $400{ }^{\circ} \mathrm{C}$, followed by pyrolysis at $900{ }^{\circ} \mathrm{C}$. However, due to incompatible polarities of the silicone oil with $\mathrm{Sb}(\mathrm{Ac})_{3}$ resulting in the inhomogeneous mixing within the preceramic polymer before pyrolysis, the Sb NPs had large size variations in the range of 10-100 $\mathrm{nm}$ and non-uniform distribution within the SiOC matrix. Herein, we attain a favorable SiOC/Sb architecture by altering the polarity of the side-chains of the polysiloxane, thereby ensuring its intimate blending with the antimony 2-ethylhexanoate $\left(\mathrm{Sb}(\mathrm{Oct})_{3}\right)$ precursor. The electro- chemical characterization of $\mathrm{SiOC} / \mathrm{Sb}$ revealed that the synthesized active material delivers a high capacity of $703 \mathrm{~mA} \mathrm{~h}$ $\mathrm{g}^{-1}$ at a current density of $74.4 \mathrm{~mA} \mathrm{~g}^{-1}$. Notably, $78 \%$ of this capacity was retained at a high current density of $2232 \mathrm{~mA} \mathrm{~g}^{-1}$. The mechanism of $\mathrm{Li}^{+}$ion insertion into $\mathrm{SiOC} / \mathrm{Sb}$ was assessed using ex situ Raman and ${ }^{29} \mathrm{Si}$ and ${ }^{7} \mathrm{Li}$ solid-state NMR spectroscopies.

\section{Results and discussion}

\section{Synthesis and characterization of $\mathrm{SiOC} / \mathrm{Sb}$ nanocomposites}

$\mathrm{SiOC} / \mathrm{Sb}$ nanocomposite was obtained in three steps that include the functionalization of a polymethylhydrosiloxane (PMHS) polymer with apolar divinyl benzene (DVB) sidechains, its subsequent gelation with $\mathrm{Sb}(\mathrm{Oct})_{3}$ precursor yield-

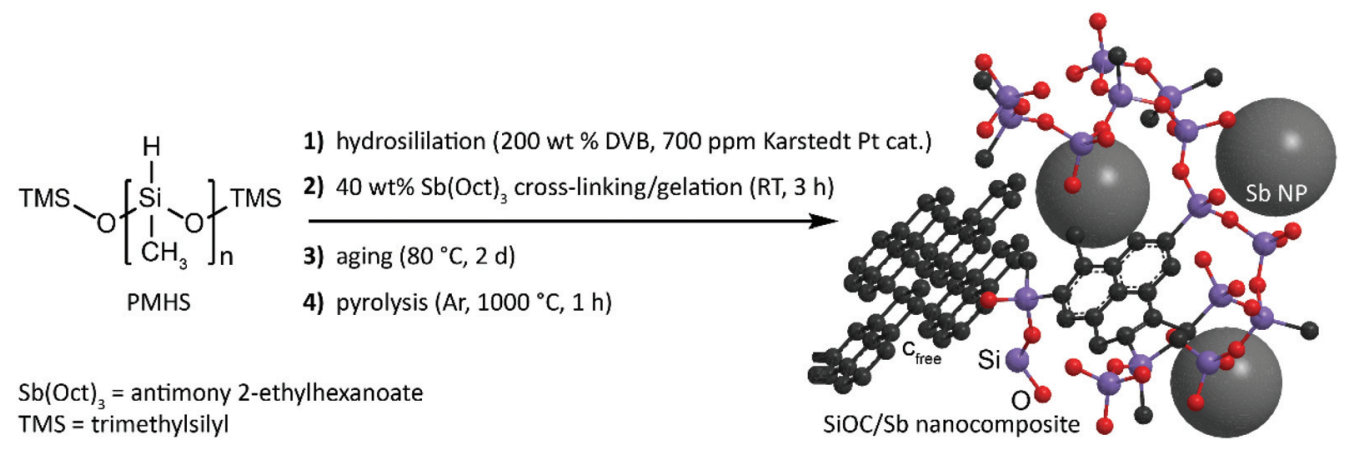

Fig. 1 Schematics of the synthetic protocol of SiOC/Sb nanocomposite.

a
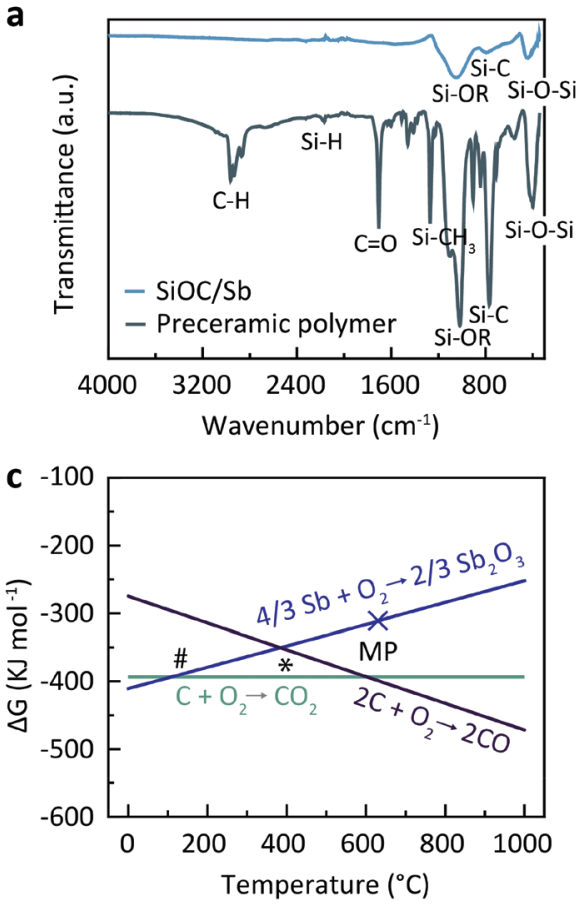

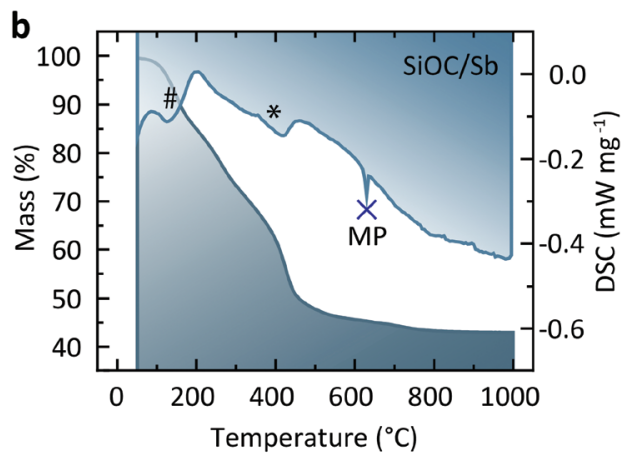

d

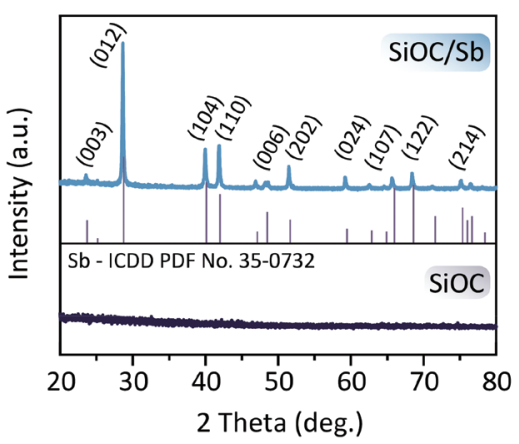

Fig. 2 (a) FTIR absorption spectra of pre-SiOC/Sb and SiOC/Sb. (b) TGA/DSC curves of pre-SiOC/Sb. (c) Ellingham diagram for Sb. (d) PXRD patterns of $\mathrm{SiOC}$ and $\mathrm{SiOC} / \mathrm{Sb}$. 
ing a preceramic SiOC/Sb polymer (pre-SiOC/Sb) and then pyrolysis of pre-SiOC/Sb at $1000{ }^{\circ} \mathrm{C}$ (Fig. 1). In short, the polymer with apolar side-chains was synthesized through a hydrosililation reaction between PMHS and $200 \mathrm{wt} \%$ of DVB. As follows from the Fourier-transform infrared spectroscopy (FTIR) measurements of pre-SiOC/Sb, the absence of the $\mathrm{Si}-\mathrm{H}$ absorption band at $2100 \mathrm{~cm}^{-1}$ demonstrates the completeness of the hydrosililation reaction of PMHS with DVB (Fig. 2a). This step was followed by the gelation of the polymer precursor with $40 \mathrm{wt} \% \mathrm{Sb}(\mathrm{Oct})_{3} . \mathrm{Sb}(\mathrm{Oct})_{3}$ was synthesized in a high yield using an anion-exchange reaction between $\mathrm{Sb}(\mathrm{Ac})_{3}$ and 2-ethylhexanoic acid in xylene at elevated temperatures. The $\mathrm{Sb}$ $(\mathrm{Oct})_{3}$ precursor was chosen because of its complete miscibility with the polysiloxane precursor and the absence of a reaction with the side-chains of polysiloxane. The pyrolysis of pre-SiOC/ $\mathrm{Sb}$ yielded a black powder $(\mathrm{SiOC} / \mathrm{Sb})$. Pure SiOC was synthesized according to our earlier report. ${ }^{18}$

To assess the mechanism of the pre-SiOC/Sb pyrolysis, a thermogravimetric analysis (TGA), coupled with differential scanning calorimetry (DSC) was performed. As follows from Fig. 2b, TGA curve of pre-SiOC/Sb remains relatively stable up to $c a .100{ }^{\circ} \mathrm{C}$. However, at higher temperatures, it drops slowly with the concomitant appearance of a DSC peak at $130{ }^{\circ} \mathrm{C}$, which is attributed to the carbothermal reduction of $\mathrm{Sb}$. We note that these results are in line with the carbothermal reduction temperature of $\mathrm{Sb}$ evidenced from Ellingham diagram (Fig. 2c). Upon further heat-treatment, we assume that the $\mathrm{Sb}$ reduction proceeds with the concomitant loss of non-crosslinked DVB (b.p. $195{ }^{\circ} \mathrm{C}$ ) at $200{ }^{\circ} \mathrm{C}$ and accelerates around $400{ }^{\circ} \mathrm{C}$. The reduced $\mathrm{Sb}$ particles then melt at $630.6^{\circ} \mathrm{C}$, which is evidenced by the appearance of a sharp DSC peak. In the temperature range of $500-1000{ }^{\circ} \mathrm{C}$, the conversion of the pre-SiOC polymer to SiOC ceramics take place with concomitant losses of organics and other volatile moieties. Interestingly, the cooling rate after pyrolysis played a decisive role in the formation of Sb NPs. For instance, the cooling rate of $5{ }^{\circ} \mathrm{C} \mathrm{min}^{-1}$ yielded clusters of aggregated Sb NPs, not homogeneously distributed within the SiOC matrix (Fig. 3a). On the contrary, a uniform dispersion of Sb NPs was observed at a cooling rate of $1^{\circ} \mathrm{C} \mathrm{min}^{-1}$. Representative high-angle annular dark field scanning transmission electron microscopy (HAADF-STEM) and transmission electron microscopy (TEM) images of the SiOC/Sb obtained at optimized cooling rate are shown in Fig. $3 \mathrm{~b}, \mathrm{c}, \mathrm{d}$, e and $\mathrm{f}$ respectively. The size of Sb NPs was in the order of 5-40 nm, while the vast majority was $c a$. $15 \mathrm{~nm}$.
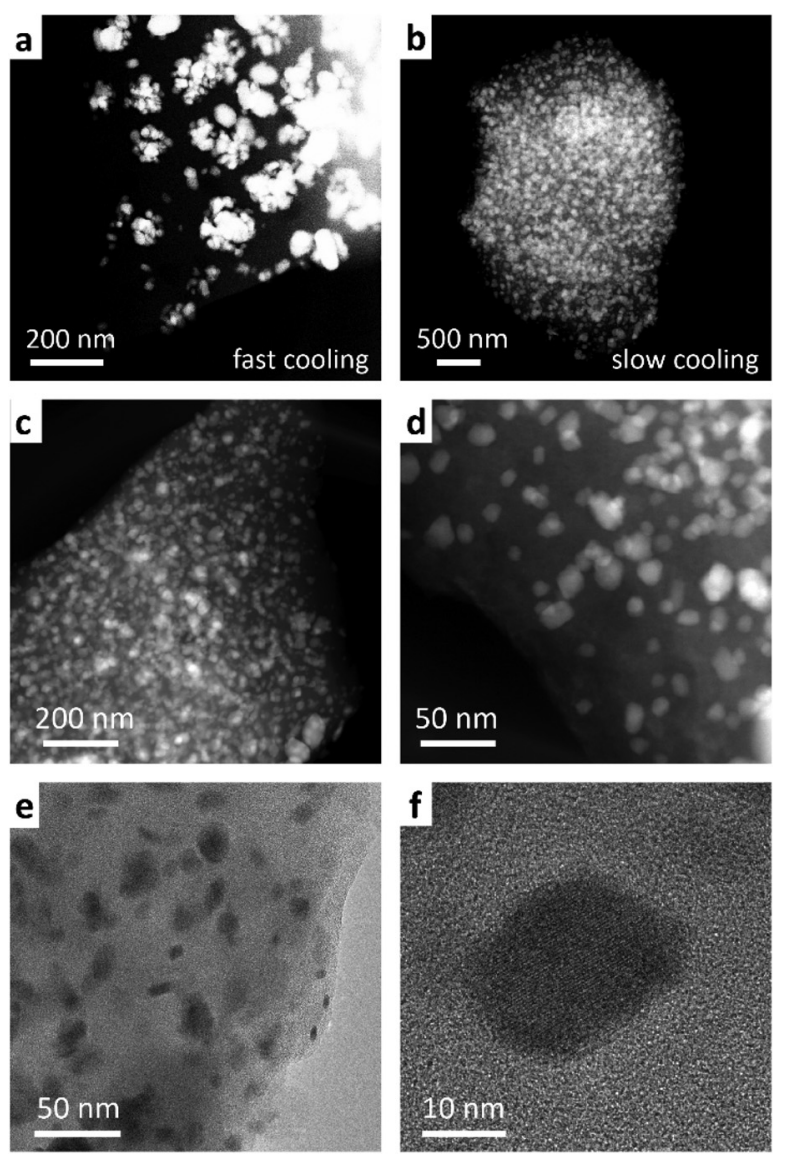

Fig. 3 HAADF STEM images of a SiOC/Sb obtained using a cooling rate of (a) $5{ }^{\circ} \mathrm{C} \mathrm{min}^{-1}$ and $(\mathrm{b}-\mathrm{d}) 1{ }^{\circ} \mathrm{C} \mathrm{min}^{-1}$, respectively. EDXS analysis of $\mathrm{SiOC} / \mathrm{Sb}$ indicates that the bright spots on HAADF-STEM images represent Sb NPs (Fig. S1 and S2 $\dagger$ ) (e and f) TEM images of SiOC/Sb.

Powder X-ray diffraction (PXRD) patterns of SiOC/Sb after pyrolysis confirmed the formation of a rhombohedral Sb structure $(a=b=0.4307 \mathrm{~nm}, c=1.1273 \mathrm{~nm}$, space group $R \overline{3} m$, ICDD PDF no. 35-0732). As follows from the elemental analysis, the content of $\mathrm{Sb}$ within the SiOC matrix was $c a$. $19.00 \mathrm{wt} \%$. The full compositions of SiOC/Sb and pure SiOC, along with the weight ratios between SiOC and $\mathrm{C}_{\text {free }}$, are shown in Table 1. Notably, the $\mathrm{C}_{\text {free }}$ content in SiOC/Sb was lower than in SiOC, although the exact same amount of DVB and PMHS was used for hydrosililation reaction in both samples. The difference can be explained by carbothermal reduction that consumes part of the carbon in the SiOC matrix. The

Table 1 Elemental analysis of $\mathrm{SiOC}$ and $\mathrm{SiOC} / \mathrm{Sb}$ nanocomposites. The explanation of the calculations of $\mathrm{C}_{\text {free }}$ and $\mathrm{SiOC}$ contents is given in the experimental section. The $\mathrm{H}$ content is less than $0.4 \mathrm{wt} \%$ in all samples

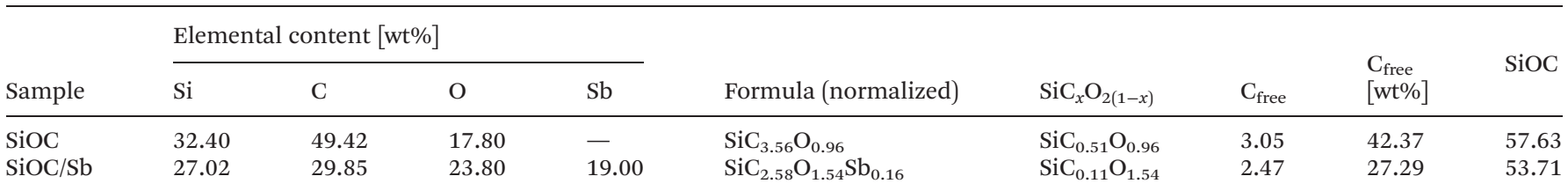


a

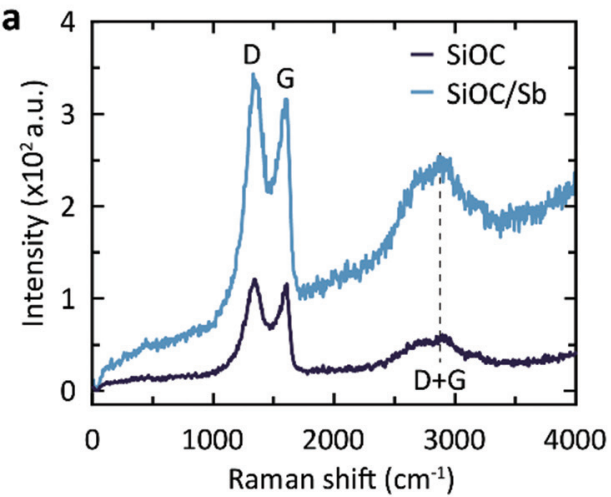

C

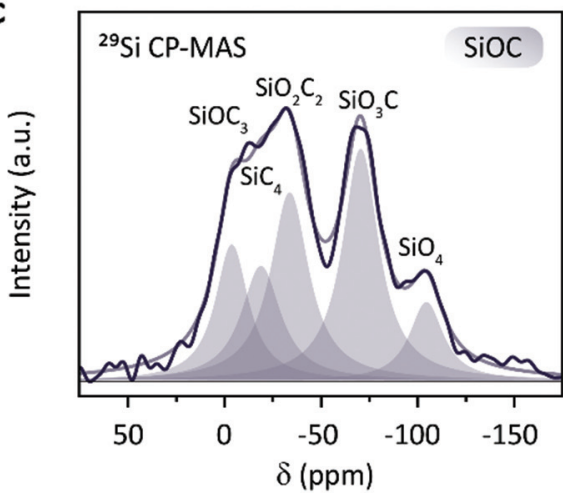

b

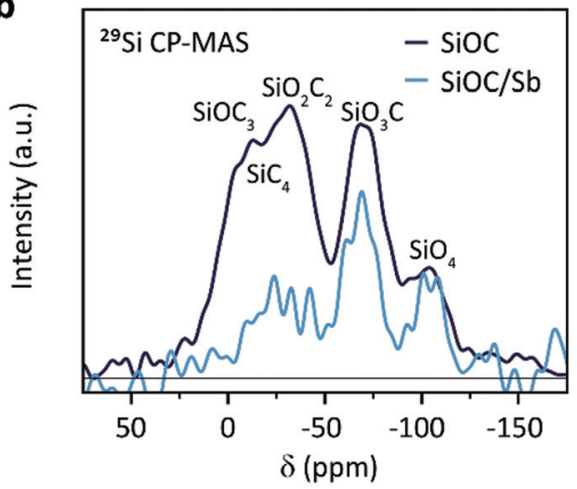

d

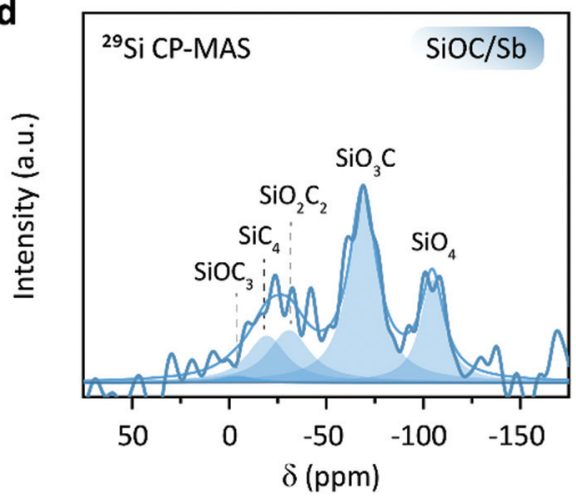

Fig. 4 (a) Raman spectra of $\mathrm{SiOC}$ and $\mathrm{SiOC} / \mathrm{Sb}$. (b) ${ }^{29} \mathrm{Si} \mathrm{CP}-\mathrm{MAS} N \mathrm{NR}$ spectra of $\mathrm{SiOC}$ and $\mathrm{SiOC} / \mathrm{Sb}$. The intensities are scaled to the $\mathrm{SiO}{ }_{4}$ peak intensity. (c) Fitted ${ }^{29} \mathrm{Si}$ CP-MAS NMR spectrum of SiOC. (d) Fitted ${ }^{29} \mathrm{Si}$ CP-MAS NMR spectrum of SiOC/Sb.

impact of the carbothermal reduction was more pronounced with higher amount of $\mathrm{Sb}(\mathrm{Oct})_{3}(50 \mathrm{wt} \%)$, seen as further decrease of $\mathrm{C}_{\text {free }}$ content down to $18.61 \mathrm{wt} \%$ (Table S1 $\dagger$ ). Notably, at $50 \mathrm{wt} \%$ of $\mathrm{Sb}(\mathrm{Oct})_{3}$, a much broader $\mathrm{Sb}$ particle size distribution (Fig. S3†), resulting in poor electrochemical performance of SiOC/Sb (Fig. S4 $\dagger$ ), was observed. The disorder of the $\mathrm{C}_{\text {free }}$ phase in SiOC/Sb and SiOC was estimated by Raman spectroscopy measurements (Fig. 4a), showing D and G carbon bands at $\approx 1350$ and $1600 \mathrm{~cm}^{-1}$. The intensity of the $\mathrm{D}$ band for SiOC/Sb is higher than for SiOC. Additionally, the secondorder region of the Raman spectrum for SiOC/Sb shows a high intensity of D $+\mathrm{G}$ combination mode at $2940 \mathrm{~cm}^{-1}$. Such features can be attributed to a high level of carbon disorder in the SiOC matrix within SiOC/Sb, which might favorably enhance its charge storage capacity.

Solid-state NMR spectroscopy with magic angle spinning (MAS) is a powerful tool to compare qualitatively the nature of the bonds surrounding the excited nucleus in a solid. To probe the nature of the local bonding in the $\mathrm{Si}-\mathrm{O}-\mathrm{C}$ network, we performed a ${ }^{29} \mathrm{Si}$ solid-state NMR analysis of the synthesized samples (Fig. $4 \mathrm{~b}-\mathrm{d}$ ). Due to the low sensitivity of the ${ }^{29} \mathrm{Si}$ nuclei, a transfer of magnetization, i.e. cross polarization (CP) from the proton traces to the ${ }^{29} \mathrm{Si}$ nuclei was effective for achieving suitable signal-to-noise ratios. The obtained chemical shifts are in good agreement with the previously reported values for $\mathrm{SiO}_{4}, \mathrm{SiO}_{3} \mathrm{C}, \mathrm{SiO}_{2} \mathrm{C}_{2}, \mathrm{SiOC}_{3}$, and $\mathrm{SiC}_{4}($ Table $\mathrm{S} 2 \dagger){ }^{33,34}$
A direct comparison of the spectra of SiOC and SiOC/Sb scaled to the intensity of the $\mathrm{SiO}_{4}$ peak reveals that the carbon content drastically decreases in the SiOC/Sb sample (Fig. 4c and d). Interestingly, the $\mathrm{SiOC}_{3}$ feature in $\mathrm{SiOC} / \mathrm{Sb}$ is almost absent, while the $\mathrm{SiO}_{3} \mathrm{C}$ character remained almost unchanged. This observation is in line with the loss of carbon during the carbothermal reduction and the increased oxygen level from the carboxylic acid groups. Furthermore, complementary ${ }^{13} \mathrm{C}$ MAS NMR measurements of SiOC and SiOC/Sb revealed that the carbothermal reduction also decreases the amount of $\mathrm{C}_{\text {free }}$ in SiOC/Sb in comparison with pure SiOC (Fig. S5†).

\section{Electrochemical performance}

The electrochemical performance of the SiOC/Sb nanocomposite is summarized in Fig. 5. For electrochemical testing, the SiOC and SiOC/Sb electrodes were prepared by mixing finely ground powders of $\mathrm{SiOC}$ and SiOC/Sb with carbon black, carboxymethyl cellulose and water. The obtained slurries were then cast onto a copper foil current collector. Resulting active material loadings were in the range of 2.3-3.1 $\mathrm{mg} \mathrm{cm}^{-2}$. All electrochemical measurements presented herein were conducted as half-cells $v s$. $\mathrm{Li}^{+} / \mathrm{Li}$ using $1 \mathrm{M} \mathrm{LiPF}_{6}$ in ethylene carbonate/dimethyl carbonate (1:1 by weight) + $3 \%$ fluoroethylene carbonate as an electrolyte. 

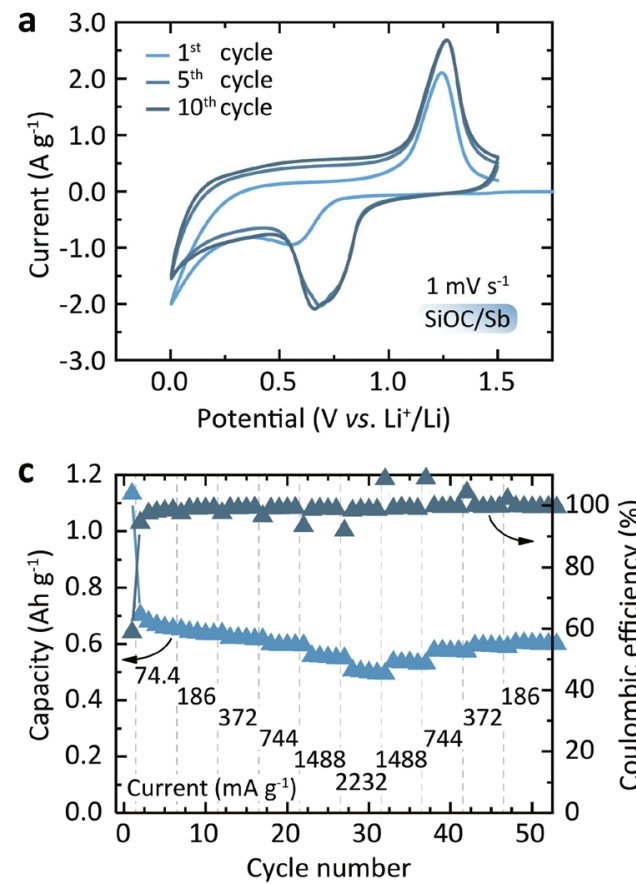
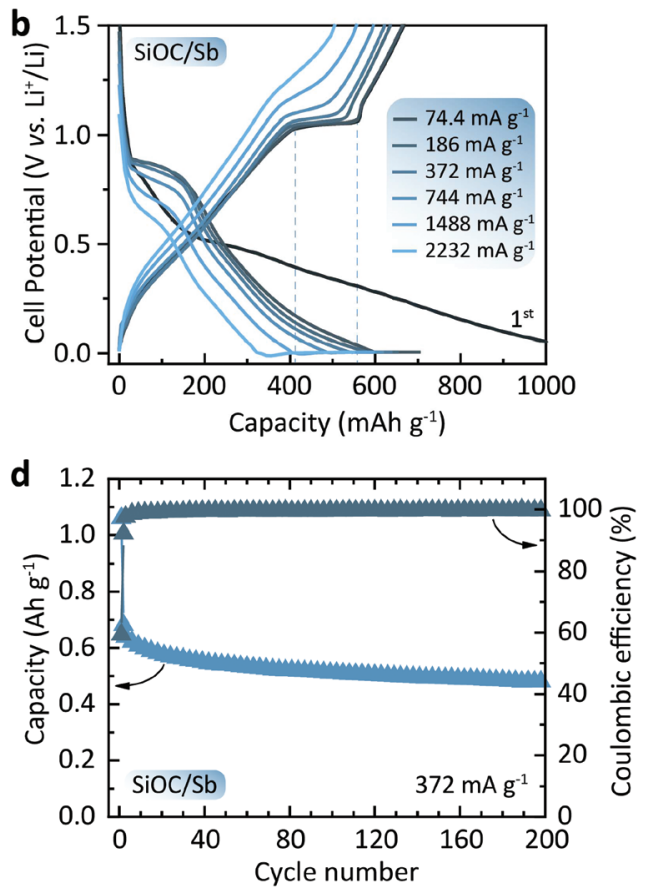

Fig. 5 (a) CV curves of SiOC/Sb measured at a scan rate of $1 \mathrm{mV} \mathrm{s}^{-1}$. (b) Galvanostatic charge-discharge curves of SiOC/Sb. The first cycle is measured at a current density of $18.6 \mathrm{~mA} \mathrm{~g}^{-1}$ and the plotted curves correspond to the $1^{\text {st }}, 2^{\text {nd }}, 7^{\text {th }}, 17^{\text {th }}, 22^{\text {nd }}, 27^{\text {th }}$ cycles. (c) Discharge capacities measured with a constant voltage step contribution at different current densities ranging from 18.6 to $2232 \mathrm{~mA} \mathrm{~g}^{-1}$. (d) Cyclic performance of SiOC/ $\mathrm{Sb}$ tested at a current density of $372 \mathrm{~mA} \mathrm{~g}^{-1}$.

Fig. 5a shows the cyclic voltametry (CV) curves of the SiOC/ $\mathrm{Sb}$ electrodes at a scan rate of $1 \mathrm{mV} \mathrm{s}^{-1}$. Upon lithiation and delithiation (cathodic and anodic cycles) of SiOC/Sb, the broad, yet distinct peaks at $c a .0 .70$ and $1.25 \mathrm{~V}$ were attributed to the alloying and dealloying of Sb NP with Li. An additional smooth increase of current in the voltage range of $0.01-1 \mathrm{~V} v s$. $\mathrm{Li}^{+} / \mathrm{Li}$ can be ascribed to the gradual lithiation/delithiation of the amorphous SiOC matrix. Fig. 5b shows the discharge and charge voltage profiles of the SiOC/Sb measured at different currents of $74.4-2232 \mathrm{~mA} \mathrm{~g}^{-1}$ and yielding capacities ranging from 703 to $549 \mathrm{~mA} \mathrm{~h} \mathrm{~g}^{-1}$ for SiOC/Sb (Fig. 5c). These measurements were performed using a constant current-constant voltage protocol with a constant voltage step at $5 \mathrm{mV}$ (see the Experimental section for details). The shape of the voltage profiles in Fig. 5b has two distinct features. A smooth part can be attributed to the lithiation of the interstitial spaces and edges of graphene within $\mathrm{C}_{\text {free }}$ in SiOC. ${ }^{35}$ The plateaus at 0.9 and 1.1 $\mathrm{V}$, eventually correspond to the lithiation and delithiation of $\mathrm{Sb}$, respectively. The comparison of discharge and charge capacities of $1133 \mathrm{~mA} \mathrm{~h} \mathrm{~g}^{-1}$ and $667 \mathrm{~mA} \mathrm{~h} \mathrm{~g}^{-1}$ for the first cycle point to the high irreversible capacity loss of $41 \%$, which can be attributed the formation of the SEI layer as well as irreversible bonding of Li ions to oxygen sites in SiOC mixed bonds.

We note that the overall reversible capacity of SiOC/Sb was higher than for pure SiOC $\left(621 \mathrm{~mA} \mathrm{~h} \mathrm{~g}{ }^{-1}\right.$ initially and $c a$. $595 \mathrm{~mA} \mathrm{~h} \mathrm{~g}^{-1}$ at $372 \mathrm{~mA} \mathrm{~g}^{-1}$ for the subsequent cycles, see
Fig. S6†). Additionally, SiOC/Sb was characterized by low polarization upon charge at high currents, resulting in only a slight increase of an average charge voltage of 0.82 and $0.87 \mathrm{~V}$ at $\mathrm{C} / 20$ and $6 \mathrm{C}$-rates, respectively. On the contrary, a higher increase of the average delithiation voltage was observed for SiOC at higher currents (from $0.71 \mathrm{~V}$ and $0.83 \mathrm{~V}$ at $\mathrm{C} / 20$ and $6 \mathrm{C}$-rate). The cyclic stability tests (Fig. 5d) of half-cells employing SiOC/ $\mathrm{Sb}$ at a current density of $0.372 \mathrm{~mA} \mathrm{~g}^{-1}$ (1C for graphite) showed a high delithiation capacity retention of $76 \%$ after 200 cycles. Notably, as observed by HAADF-STEM, no evidence of significant Sb NP pulverization or aggregation was found upon lithiation and delithiation of SiOC/Sb (see Fig. S7 and S8†).

Table 2 Overview of the observed chemical shifts and their relative integrals (Int.) in the ${ }^{7}$ Li MAS NMR spectra of lithiated and delithiated $\mathrm{SiOC}$ and $\mathrm{SiOC} / \mathrm{Sb}$

\begin{tabular}{lclll}
\hline Sample & $\delta(\mathrm{ppm})$ & Species & Int. (\%) & FWHM (Hz) \\
\hline SiOC (lith.) & 9.62 & $\mathrm{LiC}_{x} /$ rev. & 96.2 & 1903 \\
& 5.1 & SiOC/irrev. & 3.8 & 975 \\
SiOC (delith.) & 4.4 & SiOC/irrev. & 100 & 1077 \\
SiOC/Sb (lith.) & 8.89 & $\mathrm{LiC}_{x} /$ rev. & 25.4 & 2134 \\
& 6.82 & $\mathrm{LiC}_{x} /$ rev. & 41.4 & 969 \\
& 5.44 & $\mathrm{SiOC} /$ irrev. & 14.6 & 883 \\
& 5.37 & $\mathrm{Li}_{3} \mathrm{Sb}$ & 18.1 & 220 \\
& -4.2 & $\mathrm{Sb}_{\mathrm{SEI}}$ & 0.5 & 751 \\
SiOC/Sb (delith.) & 4.56 & $\mathrm{SiOC} /$ irrev. & 99.1 & 1009 \\
& -4.48 & $\mathrm{Sb} / \mathrm{SEI}$ & 0.9 & 796
\end{tabular}



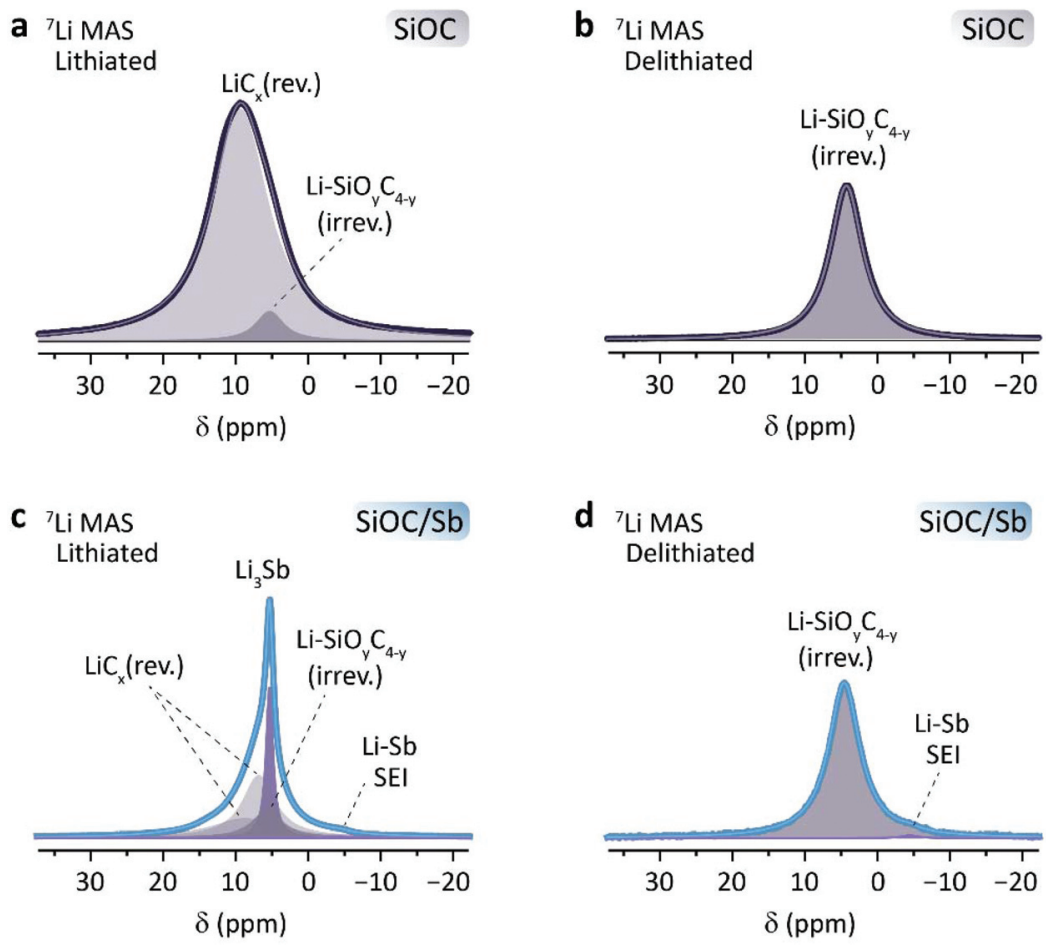

Fig. $6{ }^{7}$ Li MAS NMR (12 kHz) spectra of (a and c) lithiated and (b and d) delithiated SiOC and SiOC/Sb, respectively.

\section{Li-ion storage mechanism and particle stability}

Following the electrochemical measurements, the detailed lithiation mechanism of $\mathrm{SiOC} / \mathrm{Sb}$ was assessed by ${ }^{7} \mathrm{Li}$ solidstate NMR spectroscopy. A series of samples were recovered after electrochemical lithiation and delithiation (either fully lithiated or delithiated after a single discharge or charge). To ensure an optimal differentiation between the Li inside the SiOC composites and traces of electrolyte, the recovered materials were washed several times with EC/DMC $(1: 1$ by weight) and then thoroughly dried under inert conditions (see ESI $\dagger$ for details). ${ }^{7} \mathrm{Li}$ MAS NMR experiments showed common Li signals in all spectra between 0 and $20 \mathrm{ppm}$ (Table 2, Fig. 6). In lithiated SiOC, a broad signal at $9.6 \mathrm{ppm}$ is observed (Fig. 6a), corresponding to the reversibly inserted $\mathrm{Li}$ in the SiOC matrix. This signal has a full width at half maximum (FWHM) of $1.9 \mathrm{kHz}$ and can be attributed to the lithiation of the graphene layer edges, which are the main sites of Li-ion storage in SiOC ceramics. ${ }^{36}$ The signal line displays a slight asymmetry, indicating the presence of another species at $5.10 \mathrm{ppm}$. These species were ascribed to irreversibly inserted Li, visible for delithiated SiOC at 4.40 ppm (Fig. 6b). Upon lithiation of SiOC/Sb (Fig. 6c), five species were identified. The irreversibly inserted $\mathrm{Li}$ species within the SiOC matrix are present at $5.44 \mathrm{ppm}$. A narrow peak at $5.37 \mathrm{ppm}$ with a FWHM of $220 \mathrm{~Hz}$ is assigned to the $\mathrm{Li}_{3} \mathrm{Sb}$ species. A small shoulder at $-4.20 \mathrm{ppm}$ may be ascribed to SEI formed around the naked Sb NPs, as it remains after delithiation (Fig. 6d). Two resolvable, broad Li species at 6.82 and $8.89 \mathrm{ppm}$ can be ascribed to the reversibly inserted Li within the SiOC matrix. This is not surprising, as several Li-ion species have already been observed in SiOC with different precursors. ${ }^{36}$ However, it confirms the different nature of the $\mathrm{C}_{\text {free }}$ and mixed $\mathrm{Si}-\mathrm{O}-\mathrm{C}$ bond character in SiOC in the presence of $\mathrm{Sb}$ as already observed from Raman and ${ }^{29} \mathrm{Si}$ CP-MAS NMR spectroscopy measurements. Consequently, the NMR results show that the primary source of charge storage contribution within the SiOC/Sb nanocomposite comes from $\mathrm{SiOC} / \mathrm{C}_{\text {free }}$ active sites. In lithiated $\mathrm{SiOC} / \mathrm{Sb}$, the matrix accounts for $c a .78 .7 \%$ of the reversible $\mathrm{Li}$ sites, while the $\mathrm{Sb}$ contribution is $c a .21 .3 \%$.

\section{Conclusions}

In summary, we report the synthesis of a $\mathrm{SiOC} / \mathrm{Sb}$ nanocomposite by the pyrolysis of a preceramic single-source precursor, which was prepared through the gelation reaction of $\mathrm{Sb}$ $(\mathrm{Oct})_{3}$ and PMHS with apolar DVB side-chains. The SiOC/Sb nanocomposite displays a uniform distribution of $\mathrm{Sb}$ NPs (5-40 nm) within the SiOC matrix. SiOC/Sb showed improved Li-ion storage characteristics as compared to SiOC. In particular, SiOC/Sb exhibits high rate capability, with a charge-storage capacity of $549 \mathrm{~mA} \mathrm{~h} \mathrm{~g}^{-1}$ at a current density of $2232 \mathrm{~mA} \mathrm{~g}^{-1}$ and at high active material loadings of $2.3-3.1 \mathrm{mg} \mathrm{cm}^{-2} \cdot{ }^{29} \mathrm{Si}$ and ${ }^{7} \mathrm{Li} \mathrm{NMR}$ measurements revealed that the incorporation of $\mathrm{Sb}$ into SiOC matrix alters the carbon in the Si-O-C network, yielding different Li-ion storage sites. We suggest that future work should be focused on the improvement of the initial cou- 
lombic efficiency of SiOC/Sb, which remains a major hurdle for the commercialization of such composite electrodes.

\section{Experimental}

\section{Chemicals for the synthesis of SiOC and SiOC/Sb}

Polymethylhydrosiloxane (MW $\approx 1900$, PMHS, Sigma Aldrich), divinyl benzene (DVB, technical grade, 80\%, Sigma Aldrich), $\mathrm{Sb}$ acetate $\left(\mathrm{Sb}(\mathrm{Ac})_{3}, 99.99 \%\right.$, Sigma Aldrich), 2-ethylhexanoic acid ( $\geq 99 \%$, Sigma Aldrich), ortho-xylene (99\%, pure, Acros Organics) and platinum Karstedt's catalyst (platinum(0)-1,3divinyl-1,1,3,3-tetramethyldisiloxane complex solution in xylene, $\mathrm{Pt} \approx 2 \%$, Sigma-Aldrich) were used as received.

\section{Battery components}

Carboxymethyl cellulose (CMC, SUNROSE MAC 500LC, Nippon Paper Group), poly(vinylidene fluoride) (PVDF, $\mathrm{Mw} \approx 534000$, Sigma-Aldrich), carbon black (CB, Super P, TIMCAL, Switzerland), ethylene carbonate (EC, battery grade, BASF), LiPF $_{6}$ (battery grade, Novolyte Technologies), graphite (SLP50, TIMCAL), dimethyl carbonate (DMC, battery grade, BASF), and fluoroethylene carbonate (FEC, >98\%, TCI Chemicals) were used as received.

\section{Synthesis of $\mathrm{Sb}(\mathrm{Oct})_{3}$ precursor}

$\mathrm{Sb}(\mathrm{Oct})_{3}$ was obtained from $\mathrm{Sb}(\mathrm{Ac})_{3}$ through anion exchange. In a three-necked flask equipped with a distillation apparatus and a magnetic stir bar, $\mathrm{Sb}(\mathrm{Ac})_{3}(5.011 \mathrm{~g})$ and 2-ethylhexanoic acid $(8.25 \mathrm{~mL})$ were added to $o$-xylene $(20 \mathrm{~mL})$. The white solution was heated up to $120^{\circ} \mathrm{C}$ for $15 \mathrm{~min}$, following treatment at $240{ }^{\circ} \mathrm{C}$ for $2 \mathrm{~h}$. The mixture was then dried under vacuum at $80{ }^{\circ} \mathrm{C}$ for $12 \mathrm{~h}$ to form a yellowish liquid product. The yield was $c a .96 \%$.

\section{Synthesis of SiOC/Sb nanocomposite}

DVB $(2.5 \mathrm{~g})$ and a platinum Karstedt's catalyst $(5 \mu \mathrm{L})$ were combined into a $25 \mathrm{~mL}$ flask, and the mixture was stirred at room temperature for $10 \mathrm{~min}$. PMHS (1.25 g) was then added, and the mixture was stirred for another $10 \mathrm{~min}$. Afterwards, $\mathrm{Sb}$ $(\mathrm{Oct})_{3}(2.5 \mathrm{~g}$, corresponding to $40 \mathrm{wt} \%$ of the total preceramic polymer mixture) was added to the flask and the reaction mixture was stirred at RT for another 15 min following the formation of gel within $3 \mathrm{~h}$. The preceramic polymer gel was then aged via heat-treatment in a drying oven at $80{ }^{\circ} \mathrm{C}$ for $48 \mathrm{~h}$. Subsequently, the obtained solid was crushed and pyrolyzed in an alumina crucible under $\mathrm{Ar}$ gas at $1000{ }^{\circ} \mathrm{C}$. A heating rate was set to $5{ }^{\circ} \mathrm{C} \mathrm{min}^{-1}$, followed by a holding step of $1 \mathrm{~h}$ at the dwell temperature. The cooling rate was set at $1{ }^{\circ} \mathrm{C}$ or $5{ }^{\circ} \mathrm{C}$ $\min ^{-1}$.

\section{Characterization}

Attenuated total reflectance FTIR spectra were recorded using a Bruker Tensor 27 spectrometer (Bruker, USA) equipped with a Golden Gate ATR crystal. Raman spectra of the samples were recorded by a confocal Raman spectrometer (Renishaw, UK) using a laser beam of $488 \mathrm{~nm}$. Scanning transmission electron microscopy (STEM) investigations were performed on an aberration-corrected HD2700CS (Hitachi) operated at an acceleration potential of $200 \mathrm{kV}$. Images were recorded with a highangle annular dark field (HAADF) detector resulting in atomic number contrast (Z-contrast). TEM measurements were performed on the Talos F200X (ThermoFisher scientific, FEG, $U_{\text {acc }}$ $=200 \mathrm{kV}$ ). Powder X-ray diffraction (XRD) spectra were collected on a STOE STADI P powder X-ray diffractometer.

The contents of $\mathrm{C}, \mathrm{H}, \mathrm{O}$ and $\mathrm{Sb}$ in the SiOC and $\mathrm{SiOC} / \mathrm{Sb}$ samples were determined by elemental analysis at the Mikroanalytisches Labor Pascher (Remagen-Bandorf, Germany). The content of $\mathrm{Si}$ was estimated as the difference between the total amount of all elements $(100 \mathrm{wt} \%)$ and the sum of $\mathrm{O}, \mathrm{C}, \mathrm{H}$ and $\mathrm{Sb}$ contents (in wt\%). The $\mathrm{SiC}_{x} \mathrm{O}_{2(1-x)}$ and $\mathrm{C}_{\text {free }}=\mathrm{C}_{\text {total }}-\mathrm{C}_{x}$ formulas were applied for calculations of the ratio between $\mathrm{SiOC}$ and $\mathrm{C}_{\text {free}}$, based on the total amount of $\mathrm{Si}$, $\mathrm{O}$, and $\mathrm{C}$, which was determined from the elemental analysis. ${ }^{7} \mathrm{Li},{ }^{13} \mathrm{C}$ and ${ }^{29} \mathrm{Si}$ solid-state NMR spectroscopy was performed using a Bruker 11.7 $\mathrm{T}$ spectrometer equipped with an Avance III console and a double resonance $2.5 \mathrm{~mm}$ solid-state probe head. Samples were prepared for NMR as described in the ESI $\dagger$ and filled into a $2.5 \mathrm{~mm}$ zirconia rotor in an argon glovebox. All experiments were performed at room temperature while spinning the sample at $12 \mathrm{kHz}$ MAS frequency. The ${ }^{7} \mathrm{Li}$ chemical shifts were referenced to aqueous LiCl solution (0.1 $\mathrm{M})$, the ${ }^{13} \mathrm{C}$ chemical shifts to $\mathrm{Si}\left(\mathrm{CH}_{3}\right)_{4}$. For ${ }^{29} \mathrm{Si}$ chemical shifts, Q8M8 was used as external reference. The number of transients acquired was $4 \mathrm{k}$ for ${ }^{7} \mathrm{Li}, 100 \mathrm{k}$ for ${ }^{13} \mathrm{C}$ NMR and $16 \mathrm{k}$ for ${ }^{29} \mathrm{Si}$ NMR experiments. All ${ }^{7} \mathrm{Li}$ spectra were acquired without decoupling using one-pulse excitation sequences with a $90^{\circ}$ pulse length of $11 \mu \mathrm{s}$ and a recycle delay of $1 \mathrm{~s}$. All ${ }^{13} \mathrm{C}$ and ${ }^{29} \mathrm{Si}$ NMR spectra were acquired with a CP sequence with contact times of $2.6 \mathrm{~ms}$ and $10 \mathrm{~ms}$, respectively, and proton decoupling. A recycle delay of $1 \mathrm{~s}$ was used for both experiments.

\section{Electrode fabrication}

SiOC or SiOC/Sb (550 mg, 85\%) and carbon black (48.5 mg, $7.5 \%$ ) were ball-milled in a planetary ball-mill at $350 \mathrm{rpm}$ for $30 \mathrm{~min}$. CMC [ $48.5 \mathrm{mg}$ in water $(1.94 \mathrm{~mL}), 7.5 \%$ ] was added to the dry mass and the mixture was ball-milled in a planetary ball-mill at $350 \mathrm{rpm}$ for $30 \mathrm{~min}$. The obtained slurry was cast onto Cu-foil using a doctor-blading technique. $12 \mathrm{~mm}$ electrode disks were cut and dried overnight in a vacuum oven at $80{ }^{\circ} \mathrm{C}\left(2 \times 10^{-2} \mathrm{mbar}\right)$ prior to cell assembly. Electrode active material loadings were in the range of $2.3-3.1 \mathrm{mg} \mathrm{cm}^{-2}$. To determine the gravimetric capacities, the full mass of the SiOC and SiOC/Sb composites (85 wt\% of the total electrode material) was used.

\section{Cell assembly and testing}

Stainless-steel coin-type cells (316 L, Hohsen Corp) were assembled in a glovebox under $\mathrm{Ar}$ atmosphere $(<0.1 \mathrm{ppm}$ $\mathrm{H}_{2} \mathrm{O} / \mathrm{O}_{2}$ ) with a glass microfiber separator, $200 \mu \mathrm{L}$ of $1 \mathrm{M} \mathrm{LiPF}_{6}$ in EC: DMC (1:1 by weight) with $3 \mathrm{wt} \% \mathrm{FEC}$, and a thin disk 
of Li-metal (16 $\mathrm{mm}$ in diameter). The coin cells were electrochemically cycled after a waiting time of $2 \mathrm{~h}$ using a multichannel workstation (Astrol BAT-Flex). Cyclic voltammetry was performed using a separate multichannel workstation (MPG-2, Bio-Logic SAS). The capacity values at 74.4 and $2232 \mathrm{~mA} \mathrm{~g}^{-1}$ correspond to the $2^{\text {nd }}$ and $27^{\text {th }}$ cycle, respectively.

\section{Conflicts of interest}

There are no conflicts to declare.

\section{Acknowledgements}

This research is part of the activities of SCCER HaE, which was financially supported by the Innosuisse - Swiss Innovation Agency. P. V. W. S. and T. G. acknowledge the funding from the EMPAPOSTDOCS-II programme. The EMPAPOSTDOCS-II programme has received funding from the European Union's Horizon 2020 Research and Innovation Programme under the Marie Skłodowska-Curie grant agreement number 754364. We thank the Swiss National Science Foundation for funding of the TGA analytic instrument (SNF 206021_64024). STEM was done at the Scientific Center for Optical and Electron Microscopy (ScopeM, ETH Zürich). We thank Roland Widmer and Samuel Stolz for XPS measurements. We thank Eirini Kakkava (Optics Laboratory, EPFL) for Raman spectroscopy measurements.

\section{Notes and references}

1 L. Y. Beaulieu, K. W. Eberman, R. L. Turner, L. J. Krause and J. R. Dahn, Electrochem. Solid-State Lett., 2001, 4, A137A140.

2 J. M. Tarascon and M. Armand, Nature, 2001, 414, 359.

3 M. R. Palacín, Chem. Soc. Rev., 2009, 38, 2565-2575.

4 J. B. Goodenough and Y. Kim, Chem. Mater., 2010, 22, 587603.

5 W.-J. Zhang, J. Power Sources, 2011, 196, 13-24.

6 W.-J. Zhang, J. Power Sources, 2011, 196, 877-885.

7 N. Nitta, F. Wu, J. T. Lee and G. Yushin, Mater. Today, 2015, 18, 252-264.

8 M. Ashuri, Q. He and L. L. Shaw, Nanoscale, 2016, 8, 74103.

9 X. Shen, Z. Tian, R. Fan, L. Shao, D. Zhang, G. Cao, L. Kou and Y. Bai, J. Energy Chem., 2018, 27, 1067-1090.

10 X. Zuo, J. Zhu, P. Müller-Buschbaum and Y.-J. Cheng, Nano Energy, 2017, 31, 113-143.

11 Y. Sun, N. Liu and Y. Cui, Nat. Energy, 2016, 1, 16071.

12 C. Jiang, E. Hosono and H. Zhou, Nano Today, 2006, 1, 2833.

13 A. B. Yaroslavtsev, T. L. Kulova and A. M. Skundin, Russ. Chem. Rev., 2015, 84, 826-852.
14 N. Mahmood, T. Tang and Y. Hou, Adv. Energy Mater., 2016, 6, 1600374.

15 F.-F. Cao, H. Ye and Y.-G. Guo, in Nanostructures and Nanomaterials for Batteries: Principles and Applications, Springer Singapore, Singapore, 2019, pp. 89-158, DOI: 10.1007/978-981-13-6233-0_3.

16 M. He, K. Kravchyk, M. Walter and M. V. Kovalenko, Nano Lett., 2014, 14, 1255-1262.

17 Y. Jin, B. Zhu, Z. Lu, N. Liu and J. Zhu, Adv. Energy Mater., 2017, 7, 1700715.

18 R. J.-C. Dubey, P. V. W. Sasikumar, F. Krumeich, G. Blugan, J. Kuebler, K. V. Kravchyk, T. Graule and M. V. Kovalenko, Adv. Sci., 2019, 6, 1901220.

19 P. Colombo, G. Mera, R. Riedel and G. D. Sorarù, J. Am. Ceram. Soc., 2010, 93, 1805-1837.

20 C. Stabler, E. Ionescu, M. Graczyk-Zajac, I. Gonzalo-Juan and R. Riedel, J. Am. Ceram. Soc., 2018, 101, 4817-4856.

21 M. Halim, C. Hudaya, A. Y. Kim and J. K. Lee, J. Mater. Chem. A, 2016, 4, 2651-2656.

22 M. Wilamowska-Zawlocka, P. Puczkarski, Z. Grabowska, J. Kaspar, M. Graczyk-Zajac, R. Riedel and G. D. Sorarù, RSC Adv., 2016, 6, 104597-104607.

23 M. Graczyk-Zajac, L. M. Reinold, J. Kaspar, P. V. W. Sasikumar, G.-D. Soraru and R. Riedel, Nanomaterials, 2015, 5, 233.

24 M. Graczyk-Zajac, D. Vrankovic, P. Waleska, C. Hess, P. V. Sasikumar, S. Lauterbach, H.-J. Kleebe and G. D. Sorarù, J. Mater. Chem. A, 2018, 6, 93-103.

25 A. M. Wilson, G. Zank, K. Eguchi, W. Xing and J. R. Dahn, J. Power Sources, 1997, 68, 195-200.

26 P. Vallachira Warriam Sasikumar, E. Zera, M. GraczykZajac, R. Riedel and G. D. Soraru, J. Am. Ceram. Soc., 2016, 99, 2977-2983.

27 J. Kaspar, C. Terzioglu, E. Ionescu, M. Graczyk-Zajac, S. Hapis, H.-J. Kleebe and R. Riedel, Adv. Funct. Mater., 2014, 24, 4097-4104.

28 A. Tolosa, M. Widmaier, B. Krüner, J. M. Griffin and V. Presser, Sustainable Energy Fuels, 2018, 2, 215-228.

29 D. Vrankovic, M. Graczyk-Zajac, C. Kalcher, J. Rohrer, M. Becker, C. Stabler, G. Trykowski, K. Albe and R. Riedel, ACS Nano, 2017, 11, 11409-11416.

30 J. Kaspar, M. Graczyk-Zajac, S. Lauterbach, H.-J. Kleebe and R. Riedel, J. Power Sources, 2014, 269, 164-172.

31 Z. Wu, W. Lv, X. Cheng, J. Gao, Z. Qian, D. Tian, J. Li, W. He and C. Yang, Chem. - Eur. J., 2019, 25, 2604-2609.

32 Y. Lee, K. Y. Lee and W. Choi, Adv. Funct. Mater., 2017, 27, 1702607.

33 S. J. Widgeon, S. Sen, G. Mera, E. Ionescu, R. Riedel and A. Navrotsky, Chem. Mater., 2010, 22, 6221-6228.

34 C. G. Pantano, A. K. Singh and H. Zhang, J. Sol-Gel Sci. Technol., 1999, 14, 7-25.

35 P. Kroll, MRS Online Proc. Libr., 2011, 1313, 1-6.

36 H. Fukui, H. Ohsuka, T. Hino and K. Kanamura, ACS Appl. Mater. Interfaces, 2010, 2, 998-1008. 